DOI: 10.12957/demetra.2017.22141

\title{
Transtorno alimentar em estudantes negras de Salvador: a relação com a imagem corporal
}

\section{Eating disorders in black students from Salvador: the relationship with body image}

Liliane de Jesus Bittencourt'

Mônica de Oliveira Nunes²

1 Universidade Federal do Recôncavo da Bahia, Centro de Ciências da Saúde. Santo Antônio de Jesus-Bahia, Brasil.

${ }^{2}$ Universidade Federal do Recôncavo da Bahia, Instituto de Saúde Coletiva. Salvador-Bahia, Brasil.

Financiamento: projeto financiado pelo $\mathrm{CNPq}$, com 0 n $^{0}$ 409718/2006-8.

Correspondência / Correspondence

Liliane de Jesus Bittencourt

E-mail: liliane_bittencourt@ufrb.edu.br

\section{Resumo}

Objetivo: Avaliar até que ponto pertencer a grupos étnicos/raciais diferentes das mulheres brancas pode predispor à insatisfação com a imagem corporal e ao risco para desenvolver transtornos alimentares. Método: estudo realizado com estudantes de 15 a 30 anos, de instituições de ensino médio e universitário, público e privado. Realizado em duas etapas: a quantitativa, utilizando informações sociodemográficas e de vivência do racismo, o EAT-26, instrumento de triagem de risco para transtorno alimentar, e o BSQ, para avaliação de insatisfação com a imagem corporal; e a qualitativa, com grupos focais e história de vida. A análise foi realizada associando informações das duas etapas de investigação. Resultados: Das 626 estudantes pesquisadas, $34 \%$ tinham preocupação com a imagem corporal e $6,6 \%$, risco de comportamentos alimentares desordenados. As dez estudantes que se identificaram como negras e que participaram da etapa qualitativa da investigação não apresentavam risco para desenvolvimento de transtorno alimentar, segundo teste de screening (EAT-26), mas sete delas tinham vivenciado tais transtornos, de acordo com a história de vida. Apenas para quatro houve associação entre insatisfação com a imagem corporal e essas vivências. Discussão: há um descompasso entre os resultados dos testes quantitativos para diagnóstico de risco para esses transtornos e uma avaliação qualitativa baseada em história de vida, para pessoas de grupos étnicos/raciais diferentes. Conclusão: vivência ou percepção do racismo, associado a conflitos pessoais, familiares e sociais estão na base desses comportamentos, além da insatisfação corporal.

Palavras-chave: Transtornos Alimentares. Imagem Corporal. Raça. Mulher Negra. 


\section{Abstract}

Objective: To evaluate if belonging to ethnic/racial groups may predispose females to being dissatisfied with their body image and to the risk of developing eating disorders. Methods: A twostep study was conducted with students attending private or public high schools or universities. A quantitative step involved sociodemographic variables, experiences of racism, the Eating Attitudes Test (EAT-26), risk screening tools for eating disorder and the Body Shape Questionnaire (BSQ), in order to evaluate body image dissatisfaction. A qualitative step involved focal groups and life stories. The analysis consisted in associating data from the two segments of the study. Results: Of the 626 students evaluated, $34 \%$ were concerned with body image and $6.6 \%$ were considered at risk for eating disorders. Although the ten students who identified themselves as black were not considered to be at risk of developing an eating disorder when evaluated by the screening tools (EAT-26), seven had actually experienced eating disorders according to their life story. Conclusion: The results of the quantitative tests for diagnosis of risk of eating disorders conflicted with those of the qualitative evaluation in individuals of different ethnic/racial groups. Dissatisfaction with body image, and having experienced or perceived racism, as associated with personal, family and social conflicts, were found to be at the root of these behaviors.

Keywords: Eating Disorders. Body Image. Race/Ethnicity. Black Woman.

\section{Introdução}

A literatura científica vem exaustivamente explorando a relação existente entre a imagem corporal, percebida e sentida por jovens e adultos, e o desenvolvimento de patologias alimentares, como os transtornos anorexia e bulimia. Boa parte dos estudos comunga da assertiva de que a insatisfação vivenciada pelas pessoas em relação aos seus corpos possui uma associação direta com o desenvolvimento desses transtornos ou com comportamentos de risco para eles. ${ }^{1-4}$

Considerados importantes também são alguns grupos, que, segundo estudos, por suas características específicas acabam se tornando mais vulneráveis à insatisfação com a imagem corporal e, consequentemente, ao desenvolvimento de comportamentos alimentares desordenados. Estudantes de alguns cursos universitários, por exemplo, como psicologia, educação física e os 
ligados à área de saúde são um exemplo de grupo específico que demanda preocupação em relação a tais distúrbios. ${ }^{5-7}$ Outro fator diretamente relacionado com esta questão é a diversidade étnica ou racial, levando a manifestações diferentes e mais amplas desses comportamentos. ${ }^{8-10} \mathrm{O}$ que origina este estudo é o intuito de avaliar até que ponto pertencer a grupos étnico-raciais diferentes dos que propagandamente estão mais suscetíveis aos transtornos do comportamento alimentar, no caso, mulheres brancas, pode também predispor à insatisfação com a imagem corporal e ao risco para desenvolvê-los. Estudos internacionais vêm avaliando esta relação. O estudo de Grilo, Lozano $\&$ Masheb $^{11}$ demonstrou que as mulheres negras precisam estar significativamente pesadas para expressarem insatisfação e preocupação com seu corpo e, por conseguinte, buscarem tratamento para a compulsão alimentar. Na África do Sul, as adolescentes negras urbanas têm mais insatisfação corporal, desejo de emagrecer e vulnerabilidade para transtornos do comportamento alimentar que as adolescentes negras da zona rural. ${ }^{12}$ Nos EUA, um estudo chegou à conclusão que quanto mais identificadas com seu grupo étnico, menos as mulheres negras internalizam os ideais sociais de atratividade e beleza americana e, consequentemente, menos se preocupam com a imagem corporal e desenvolvem transtornos do comportamento alimentar. ${ }^{13}$ Apesar de a insatisfação corporal poder fazer parte das preocupações de qualquer indivíduo, sem que isso signifique um transtorno, sendo apenas expressão de cuidado consigo e com sua saúde, este estudo procurou esclarecer como esses fatores se interligam aqui no Brasil e, especificamente, na cidade de Salvador, caracteristicamente praiana e de grande população negra. Por isso, o objetivo aqui estabelecido foi avaliar a predisposição para insatisfação com a imagem corporal de mulheres negras e o risco de desenvolvimento dos transtornos alimentares.

\section{Método}

Os critérios de seleção foram adolescentes e adultos jovens, do sexo feminino, estudantes em escolas de ensino médio e em instituições de ensino superior. na faixa etária de 15 a 30 anos, residentes na cidade de Salvador, no Estado da Bahia. Elegeram-se para o estudo instituições de ensino de nível médio, localizadas no centro da cidade, devido à confluência de estudantes de outros bairros para essas escolas, a fim de garantir a diversidade racial e social; e instituições de ensino superior que tivessem os cursos de nutrição, medicina, enfermagem, educação física e psicologia, devido a sua relação com o corpo e alimentação, e pela sugestão da literatura sobre o tema de serem os que abrigam mais pessoas em risco de desenvolverem transtornos alimentares. ${ }^{8,14-17}$

Para definição da amostra, partiu-se de um estudo-piloto realizado com 81 estudantes de nutrição, oriundas de duas faculdades, uma pública e outra privada, devido à inexistência, à época, de estudos nacionais ou locais que levassem em consideração a diversidade étnico/racial. Nesse, o resultado foi de 8,6\% para comportamentos de risco para transtornos alimentares, não 
oferecendo discrepância em relação aos resultados encontrados nos estudos de prevalência para este transtorno. ${ }^{5,18}$ Assumiu-se 0,036 como erro absoluto máximo aceitável, um poder de amostra de $80 \%$ e nível de significância de $95 \%$. O tamanho da amostra estimado ficou em torno de 411 mulheres, mas foi ampliado para 822, devido à aplicação do desenho de efeito $(2,0)$, a fim de dar conta do possível efeito de conglomeração em função do procedimento de amostragem aleatória em dois estágios.

À época, havia 32 instituições de ensino médio (11 públicas e 21 particulares) e 19 de ensino superior (17 particulares e 2 públicas) elegíveis para coleta de dados. Dessas, foram selecionadas aleatoriamente 12 escolas de ensino médio (4 públicas e 8 particulares) e 8 instituições de ensino superior (2 universidades públicas e 6 faculdades particulares). No segundo estágio da amostragem, procedeu-se ao sorteio de, ao menos, duas turmas, com média de 20 alunos, em cada uma das instituições de ensino selecionadas no primeiro estágio. Foi possível obter uma amostra de 626 estudantes, no período de novembro de 2008 a agosto de 2009, representando, aproximadamente, $76 \%$ do número amostral definido estatisticamente. Uma das dificuldades em relação a essa coleta esteve relacionada com o tema da pesquisa, levando à recusa de algumas alunas.

O estudo ocorreu em duas etapas. A primeira, quantitativa, resultou da aplicação de um instrumento contendo um questionário que coletou informações sobre identificação das jovens, dados sociais (renda familiar e religião), peso e altura referidos, satisfação corporal, vivência do racismo e percepção de existência de rede de apoio social e familiar (questionário adaptado da pesquisa da Fundação Perseu Abramo sobre Discriminação Racial e Preconceito de cor no Brasil); o questionário para avaliação do risco de desenvolvimento de transtorno alimentar (Eating Attitude Test - EAT-26); e o Body Shape Questionnaire (BSQ), que visava caracterizar a imagem corporal dessas mulheres.

A identificação da raça/cor ocorreu por autodeclaração, seguindo os critérios do Instituto Brasileiro de Geografia e Estatística (IBGE) - branca, preta, parda, amarela e indígena.

A avaliação antropométrica foi realizada utilizando dados de peso e altura referidos (na fase quantitativa) e aferidos (na etapa qualitativa). A literatura corrobora esta prática quando revela que as avaliaçóes baseadas apenas em dados referidos correspondem aos dados aferidos e, portanto, são válidas, podendo ser utilizadas quando há necessidade de oferecer maior praticidade ao estudo. ${ }^{19,20}$ Para a estimativa do Índice de Massa Corporal foram seguidas as orientações do Sistema de Vigilância Alimentar e Nutricional do Ministério da Saúde, ${ }^{21}$ que recomenda a análise do IMC para adultos de acordo com os valores de referência $\left(<18,5 \mathrm{~kg} / \mathrm{m}^{2}\right.$, magreza; 18,5 a 24,9 $\mathrm{kg} / \mathrm{m}^{2}$, eutrofia; 25 a $29,9 \mathrm{~kg} / \mathrm{m}^{2}$, sobrepeso; $\geq 30 \mathrm{~kg} / \mathrm{m}^{2}$, obesidade). O IMC entre 17,0 e $18,4 \mathrm{~kg} /$ $\mathrm{m}^{2}$ foi classificado como magreza grau I; entre 16,9 e $16,0 \mathrm{~kg} / \mathrm{m}^{2}$, como magreza grau II; e menor que $16,0 \mathrm{~kg} / \mathrm{m}^{2}$, como magreza grau III, de acordo com a recomendação da Organização Mundial 
de Saúde de $1997 .^{22}$ Para a avaliação dos percentis entre as adolescentes, utilizou-se a curva de IMC por idade para meninas de 5 a 19 anos, da Organização Mundial de Saúde e adotada pelo Ministério da Saúde. ${ }^{23}$

Para o presente artigo, utilizou-se o EAT na versão resumida, em português, com 26 questões autoaplicáveis, permitindo seis opções de resposta. Cada questão divide-se em 3 escalas do tipo Lickert, variando de 0 a 3 pontos, de acordo com a escolha: nunca, raramente ou às vezes $=0$; frequentemente $=1$; muito frequentemente $=2$; sempre $=3$. Um escore $>20$ revela risco para transtornos alimentares. ${ }^{24-28}$ Também foi utilizado o Body Shape Questionnaire (BSQ) na versão em português, autoaplicável, com 34 questões que mensuram a preocupação com o corpo e o peso. Para cada questão eram oferecidas 6 opções de respostas (nunca $=1$; raramente $=2$; às vezes $=$ 3 ; frequentemente $=4$; muito frequentemente $=5$; sempre $=6$ ). Um resultado menor que 80 indica ausência de preocupação com a imagem corporal; de 81 a 110, preocupação leve; 111 a 140, preocupação moderada; acima de 140, grave preocupação com a imagem corporal. ${ }^{24,28-30}$ Os dados coletados foram digitados em dupla entrada e analisados com o software SPSS, versão 15, obtendo-se as medidas descritivas, número de casos (n) e prevalência dos agravos.

Na segunda etapa, realizou-se uma investigação qualitativa através de grupos focais e entrevistas individuais com história de vida. Optou-se por realizar quatro grupos focais, dois grupos com jovens de instituições de nível médio e dois com estudantes de instituições de ensino superior, pública e privada, respectivamente. As alunas foram selecionadas para participar dos grupos focais a partir da análise do banco de dados da etapa quantitativa, levando em consideração os seguintes critérios: indicação para transtorno alimentar, preocupação com imagem corporal, raça/cor, religião, renda, magreza e sobrepeso ou obesidade. Foram convidadas por e-mail e telefone. Foi definido que cada grupo focal seria realizado com um máximo de 12 estudantes, e para tentar garantir a presença foram convidadas aproximadamente 40 alunas (respeitando uma proporção aproximada de 3:1, ou seja três convidadas para a possibilidade de uma participação). Só houve êxito para realização de dois grupos focais, com as estudantes de ensino médio público (participaram cinco alunas) e com as estudantes de instituição privada (participaram quatro alunas). Toda a atividade foi registrada em gravador analógico. Além disso, todas as expressões ou informações que não poderiam ser gravadas foram registradas pela relatora. Cada grupo levou. em média. 1h30.

As entrevistas foram realizadas com alunas selecionadas no grupo focal e da análise do banco de dados, levando em consideração o risco para transtorno alimentar ou alguma característica que indicasse uma suspeição em relação a problemas alimentares ou corporais. Procurou-se garantir a diversidade racial, de faixa etária e pertencimento social. As alunas foram convidadas por telefone, momento em que era combinada a data, o horário e o local para realização das entrevistas, que foram orientadas por um roteiro elaborado pela equipe e registradas em gravadores analógicos e/ ou digitais e depois transcritas por pessoas contratadas para tal fim. Cada entrevista era conduzida 
por dois pesquisadores da equipe e durava em torno de $2 \mathrm{~h}$. O tempo entre a aplicação dos questionários e a realização das entrevistas variou entre 3 e 8 meses. No total, foram realizadas 12 entrevistas, mas uma foi perdida por problemas técnicos. As estudantes tinham entre 18 e 26 anos; oito eram universitárias e três estudantes do nível médio. Quanto ao pertencimento étnico/ racial, seis se definiram como preta, três como branca, uma amarela e uma parda. Quanto à renda, cinco possuíam renda familiar entre um e três salários mínimos, duas viviam com renda acima de três até cinco salários mínimos, três viviam com renda acima dos cinco salários mínimos e uma não declarou a renda.

Partimos dos resultados adquiridos através do EAT-26, do BSQ e das informações obtidas nas entrevistas, grupos focais e no primeiro questionário para realizar a análise de que trata este artigo. As estudantes foram divididas em dois grupos: negras - as que se definiram como pretas - e não negras - as que assumiram outro pertencimento étnico/racial, incluindo aí as pardas, devido à ambiguidade desta definição. A análise do risco para desenvolvimento dos transtornos alimentares e preocupação com o formato e tamanho corporal foram avaliados através dos pontos de corte estabelecidos na literatura para os resultados do EAT e do BSQ, mas também pela análise qualitativa das respostas fornecidas por cada aluna entrevistada ou que participou do grupo focal.

As narrativas dos grupos focais e das entrevistas foram submetidas à análise através de uma abordagem hermenêutica, que, nesse caso, configura-se como a compreensão dos sentidos atribuídos à experiência vivida pelas participantes integrantes do estudo. Interessou-nos captar o sentido atribuído às vivências de jovens que ou desenvolveram ou estavam no limiar de desenvolverem transtornos de origem alimentar. Para tal, a hermenêutica, ou a compreensão que advém da interpretação dos sentidos da vida quotidiana, das experiências ou da realidade, é a maneira de se aproximar dos significados que estas assumem num contexto de desordens, que estão na base do sofrimento de várias mulheres.

Para compreender os sentidos atribuídos por jovens escolares as suas experiências corporais e alimentares, foi preciso uma aproximação da doxa, ou conjunto de crenças, opiniões e compreensões do mundo social ao qual elas fazem parte. A interpretação da doxa necessitou estar associada ao conhecimento das condições sociais e históricas de desenvolvimento e construção das formas simbólicas, bem como das interações existentes num contexto espaço/temporal determinado. ${ }^{31} \mathrm{~A}$ revelação desses sentidos dependeu também da análise de como as narrativas surgidas do processo de relação entrevistador(a)/entrevistado foram organizadas. Narrativa aqui tomada como uma maneira de ressignificar a experiência, na medida em que ela sai do domínio particular e se torna pública, através do diálogo possível com um outro, que se dá através da linguagem. ${ }^{32}$

Para garantir os princípios éticos dessa investigação, foram solicitadas autorizações dos dirigentes das instituições de ensino, bem como um termo de consentimento livre e esclarecido 
foi assinado pelas alunas maiores de dezoito anos e pelos pais ou responsáveis das menores de idade. Para manter o sigilo quanto à identificação das jovens, foram estabelecidos codinomes utilizando o seguinte código: as estudantes de nível médio receberam nomes relacionados ao mar, e as universitárias foram identificadas com nomes associados ao céu. Essa investigação foi aprovada pelo comitê de ética do Instituto de Saúde Coletiva e financiado pelo CNPq (projeto no 409718/2006-8).

\section{Resultado}

Das 626 estudantes que participaram dessa investigação, 34\% delas demonstravam preocupação com a imagem corporal e $6,6 \%$, risco de comportamentos alimentares desordenados. A preocupação com a imagem corporal e comportamentos alimentares desordenados estava presente em 5,6\% da amostra. Quando avaliamos as dez estudantes que se identificaram como negras e que participaram das entrevistas e/ou grupos focais nenhuma delas apresentava risco para transtorno alimentar de acordo com o EAT-26, pois exibiram valor para o teste $\leq 20$, mas quatro apresentaram preocupação com sua imagem corporal, segundo o BSQ. No entanto, ao avaliar as narrativas, percebeu-se que alguns sinais e sintomas desses transtornos estiveram presentes na vida de sete jovens, sejam relacionados as suas próprias experiências corporais ou envolvendo alguém próximo, seja um familiar ou amigo.

As três jovens (Raio de Sol, Raio de Luz e Tainaçá) que não apresentaram sinal ou sintoma de risco para transtorno alimentar em suas histórias de vida estavam insatisfeitas com sua imagem corporal e uma delas, Tainaçá, apresentou uma grave preocupação com o formato e tamanho do corpo, contrariando as evidências científicas de associação entre insatisfação com a imagem corporal e desenvolvimento de síndromes alimentares. Estrela, Taína e Janaína, apesar de estarem satisfeitas com sua imagem corporal e de, pelo BSQ, não evidenciarem nenhum tipo de preocupação com o formato e tamanho corporal, apresentaram nas suas histórias de vida algum tipo de vivência relacionada ao transtorno alimentar (Quadro 1). 
Quadro 1. Perfil corporal, satisfação com a imagem corporal e risco para transtorno alimentar nas estudantes negras.

\begin{tabular}{|c|c|c|c|c|c|c|c|c|c|c|c|}
\hline \multirow{2}{*}{\multicolumn{2}{|c|}{ Participação }} & \multicolumn{10}{|c|}{ NEGRAS } \\
\hline & & $\mathrm{E}$ & GF & GF & $\mathrm{GF} / \mathrm{E}$ & GF & $\mathrm{E}$ & $\mathrm{E}$ & $\mathrm{E}$ & $\mathrm{E}$ & $\mathrm{GF} / \mathrm{E}$ \\
\hline \multicolumn{2}{|l|}{ Nome } & Estrela & Taína & Cora & $\begin{array}{c}\text { Raio } \\
\text { de Sol }\end{array}$ & Janaína & $\begin{array}{c}\text { Raio } \\
\text { de Luz }\end{array}$ & Galáxia & Tainaçá & Marisol & Sereia \\
\hline \multicolumn{2}{|c|}{$\begin{array}{l}\text { Índice } \\
\text { de Massa } \\
\text { Corporal } \\
\text { (referido/ } \\
\text { aferido) }\end{array}$} & $\mathrm{ET}$ & $\mathrm{MII} / \mathrm{I}$ & $\begin{array}{l}\mathrm{SB} / \\
\mathrm{ET}\end{array}$ & M II/I & M I/ET & M III & $\mathrm{ET}$ & OB & $\mathrm{ET}$ & OB \\
\hline \multicolumn{2}{|c|}{$\begin{array}{l}\text { Resultado } \\
\text { Body Shape } \\
\text { Questionnaire }\end{array}$} & $\mathrm{S} / \mathrm{PC}$ & $\mathrm{S} / \mathrm{PC}$ & $\mathrm{S} / \mathrm{PC}$ & $\mathrm{S} / \mathrm{PC}$ & $\mathrm{S} / \mathrm{PC}$ & $\mathrm{S} / \mathrm{PC}$ & PM & PG & PL & $\mathrm{PM}$ \\
\hline \multicolumn{2}{|c|}{$\begin{array}{l}\text { Satisfação } \\
\text { com a } \\
\text { imagem } \\
\text { corporal }\end{array}$} & SIM & SIM & NÃO & NÃO & SIM & NÃO & NÃO & NÃO & NÃO & NÃO \\
\hline \multicolumn{2}{|c|}{$\begin{array}{l}\text { Resultado } \\
\text { Eating } \\
\text { Attitude Test }\end{array}$} & 20 & 13 & 3 & 6 & 6 & 15 & 4 & 17 & 5 & 20 \\
\hline \multicolumn{2}{|c|}{$\begin{array}{l}\text { Sinais e } \\
\text { sintomas de } \\
\text { Transtorno } \\
\text { Alimentar na } \\
\text { História de } \\
\text { Vida }\end{array}$} & SIM & SIM & SIM & NÃO & SIM & NÃO & SIM & NÃO & SIM & SIM \\
\hline \multicolumn{12}{|c|}{ Legenda $\quad$ Significado } \\
\hline $\mathrm{E}$ & \multicolumn{11}{|c|}{ Entrevista } \\
\hline GF & \multicolumn{11}{|c|}{ Grupo focal } \\
\hline $\mathrm{ET}$ & \multicolumn{11}{|c|}{ Eutrófico } \\
\hline MII & \multicolumn{11}{|c|}{ Magreza grau II } \\
\hline MI & \multicolumn{11}{|c|}{ Magreza grau I } \\
\hline SB & \multicolumn{11}{|c|}{ Sobrepeso } \\
\hline OB & \multicolumn{11}{|c|}{ Obesidade } \\
\hline $\mathrm{S} / \mathrm{PC}$ & \multicolumn{11}{|c|}{ Sem preocupação com formato e tamanho do corpo } \\
\hline PM & \multicolumn{11}{|c|}{ Preocupação moderada } \\
\hline PL & \multicolumn{11}{|c|}{ Preocupação leve } \\
\hline PG & \multicolumn{11}{|c|}{ Preocupação grave } \\
\hline
\end{tabular}


O singular na história de Estrela é que ela acredita já ter tido episódio de transtorno alimentar, pois quando trabalhava de telemarketing, o estresse e ansiedade a faziam comer compulsivamente. Expressava satisfação com sua aparência em vários momentos da entrevista, no entanto a prática de atividade física e as dietas pareciam ser uma consequência ou estar relacionada com esse comportamento alimentar exagerado. Além disso, a situação de sua mãe, que tinha um hábito alimentar característico de anorexia, tendo sido internada em consequência disso, a fez refletir sobre a importância desse cuidado. O suposto comportamento anoréxico da mãe e também a existência de pessoas "gordinhas" na família pareciam reforçar esta preocupação com o comer e a comida.

A presença de sinais de transtorno alimentar para Taína e Janaína se expressava através de comportamentos de pessoas da família. Taína referia satisfação com seu corpo e não conseguia entender a insatisfação da sua irmã, que, apesar de ter um corpo, segundo ela, "bem bonito, bem definidinho", percebia-se gorda e utilizava-se de artifícios os mais variados para conseguir emagrecer. Janaína se preocupava com o comportamento da sua cunhada, que mesmo tendo um corpo lindo, passava muitas horas em jejum, com uma alimentação diária que se limitava a um copo de suco com bolachas e chá. Ela disse: "ela já tá ficando com os olhos fundos, com uma aparência triste, de tanto fazer jejum."

Cora, Galáxia, Marisol e Sereia foram as que confirmaram a relação entre insatisfação com a imagem corporal e sinais e sintomas associados ao transtorno alimentar, como referido na literatura, mesmo o resultado do EAT-26 não demonstrando isso.

Apesar de o resultado do BSQ ter sido abaixo do ponto de corte estimado, há uma diferença para mais entre peso e altura referidos por Cora e os dados aferidos. Essa diferença pode ser resultado de uma falta de conhecimento real sobre seu corpo ou uma percepção exagerada que contradiz o resultado do teste e o fato de ter respondido estar satisfeita com suas características físicas e não querer modificá-las. Apesar do tempo de 8 meses entre os dois momentos, a diferença do peso referido para o aferido é muito grande (12kg), o que também pode ser explicado por uma possível dieta radical para emagrecimento, já que manifestou uma atitude concreta no sentido de perder peso. De qualquer modo, a insatisfação com a imagem corporal fica evidenciada nessas contradições e na sua narrativa. A sua mãe parecia ter uma influência grande nessa preocupação com o corpo, pois reclamava de a mãe comentar com as pessoas que ela estava gorda. Confessou que chegou a achar interessante a pessoa emagrecer vomitando.

Eu até achava legal isso, porque é diferente a pessoa tá gorda e isso tudo que a pessoa come a pessoa vomita, mas eu penso também que com o tempo a pessoa vai vendo as consequências, quando a pessoa vomita não fica nada no estômago e aí vem a doença (Cora, negra). 
A avaliação qualitativa das respostas dadas no EAT-26 e BSQ comprova a preocupação em não engordar, expressa na entrevista de Marisol. Conta já ter engordado quando era mais jovem, devido ao uso de medicamento, o que provocou essa preocupação com a gordura corporal. Já fez dietas, segundo ela, malucas, como se alimentar apenas com um copo de suco de laranja com duas bolachas do tipo cream cracker. "Quase ficou doente" devido a esse comportamento.

Sereia relata ter vivido episódios bulímicos de forma consciente e planejada. Sempre teve uma alimentação desequilibrada, com várias horas em jejum entre a refeição da manhã e da noite, devido à falta de tempo no trabalho. Quando começou a engordar, resolveu provocar o vômito após as refeições. Apesar de a estratégia não ter resolvido seu excesso de peso e de se sentir bem com tal comportamento, decidiu parar por medo das consequências para a saúde.

(...) Ah, me sentia bem porque comia, comia, ai quando eu botava me sentia, me sentia bem. (...) Sentia um alivio de desgaste de barriga cheia demais, por que às vezes eu comia muito, mas um alivio de um pouco de barriga vazia assim, né. Agora ruim era vomitar, porque a ânsia de vomito, né. Mas depois justamente eu sentia um pouco aliviada, com o estômago mais vazio. Já mais leve (Sereia, negra).

Os comentários das outras pessoas em relação ao seu corpo e o quanto estava engordando foi um fator incentivador para o início do comportamento bulímico, mas o conhecimento desse comportamento como estratégia de emagrecimento aconteceu através de uma novela. Foi também a partir de um programa de televisão que entendeu os perigos dessa conduta e resolveu parar. Mesmo não provocando mais o vômito, à época da entrevista comia de forma compulsiva, escondido às vezes, utilizando outras estratégias para emagrecer.

Eu tive época que tomava chá que dava disenteria, ficava com fome praticamente o dia todo, à noite eu não janto, não como nada, que comer à noite, ai é que engorda, eu já não como nada à noite, e isso daí assim, às vezes de manhã também tem vez que come, tem vez que não come, às vezes só meio dia mesmo, como ali (Sereia, negra).

Galáxia utilizava-se da mesma estratégia de Sereia para emagrecer. Comer e depois provocar o vômito foi algo adotado por ela quando tinha entre 15 e 16 anos. Na sua narrativa disse que só fez isso umas duas vezes, porque tinha consciência que era uma doença. Uma novela também foi o veículo de apresentação desse comportamento. Se na adolescência ela diminuía o consumo de alimentos para poder emagrecer, na época da entrevista tinha um comportamento compulsivo.

Às vezes depende do dia, tipo assim às vezes 3 horas da tarde eu vou ao supermercado e compro um monte de coisa, como igual uma desesperada. Às vezes não, é pela manhã, fico pela manhã comendo, às vezes é de noite, eu como de ficar passando mal (Galáxia, negra). 
Para compensar tal comportamento ela ficava períodos sem comer. Dizia que, se comesse muito em um turno, deixava de comer no outro, se comesse muito em um dia, no outro procurava comer menos. Chama a atenção no relato de Galáxia o sentimento de culpa que acompanha tal comportamento, o que não impedia a continuidade consciente do mesmo. Referiu, no momento da entrevista, que deixava de comer por outros motivos, que não fosse a vontade de emagrecer ou a tentativa de cuidado com o corpo. Alegava sentir muita ansiedade; no entanto, o mais preocupante é a afirmação de que tinha o hábito de se castigar quando estava se sentindo mal. Parece que insatisfações outras que não apenas com o corpo estavam na base dessa ansiedade, do comportamento compulsivo de Galáxia e da vontade de se maltratar.

Hoje em dia eu como muito, às vezes me sinto culpada por ter comido demais, porque a barriga fica grande, às vezes fico sem comer, mas fico sem comer por outros motivos, não pra emagrecer; hoje em dia eu meio que abandonei de lado essa questão com o corpo, eu me preocupo sim em não expor, mas de tá cuidando dele não (Galáxia, negra).

Esses resultados qualitativos informam que, apesar de não terem sido detectadas como pessoas com comportamento de risco para os transtornos alimentares através dos testes quantitativos, essas estudantes estavam suscetíveis aos mesmos, já tendo inclusive vivenciado tais comportamentos.

Entre as estudantes não negras, os sinais e sintomas de risco para os transtornos alimentares só tiveram correspondência com a insatisfação com a imagem corporal e com a preocupação com o formato e tamanho do corpo para Jaciara. Para as estudantes que participaram do grupo focal, a atitude evasiva quanto as suas próprias experiências corporais resultou em alusão apenas a situações vividas por amigos e/ou colegas (Quadro 2). 
Quadro 2. Perfil corporal, satisfação com a imagem corporal e risco para transtorno do comportamento alimentar nas estudantes não negras.

\begin{tabular}{|c|c|c|c|c|c|c|c|c|c|}
\hline \multirow{2}{*}{\multicolumn{2}{|c|}{ Participação }} & \multicolumn{8}{|c|}{ NÃO NEGRAS } \\
\hline & & GF & GF & GF & GF & $\mathrm{E}$ & $\mathrm{E}$ & $\mathrm{E}$ & $\mathrm{E}$ \\
\hline \multicolumn{2}{|l|}{ Nome } & Sirena & Talassa & Rubía & Marina & Céu & Rubídea & Jaciara & Dalva \\
\hline \multicolumn{2}{|c|}{$\begin{array}{l}\text { Índice de Massa } \\
\text { Corporal (referido/ } \\
\text { aferido) }\end{array}$} & ET & $\mathrm{SB}$ & M II/I & $\mathrm{MI} / \mathrm{ET}$ & SB & OB & $\mathrm{ET}$ & ET \\
\hline \multicolumn{2}{|c|}{$\begin{array}{l}\text { Resultado Body } \\
\text { Shape Questionnaire }\end{array}$} & $\mathrm{S} / \mathrm{PC}$ & $?$ & $\mathrm{~S} / \mathrm{PC}$ & $\mathrm{S} / \mathrm{PC}$ & PL & PM & PG & $\mathrm{S} / \mathrm{PC}$ \\
\hline \multicolumn{2}{|c|}{$\begin{array}{l}\text { Satisfação com a } \\
\text { imagem corporal }\end{array}$} & NÃO & NÃO & NÃO & NÃO & NÃO & NÃO & NÃO & SIM \\
\hline \multicolumn{2}{|c|}{$\begin{array}{l}\text { Resultado Eating } \\
\text { Attitude Test }\end{array}$} & 6 & $?$ & 4 & 11 & 6 & 9 & 25 & 5 \\
\hline \multicolumn{2}{|c|}{$\begin{array}{l}\text { Sinais e sintomas } \\
\text { de Transtorno } \\
\text { Alimentar na } \\
\text { História de Vida }\end{array}$} & SIM & SIM & NÃO & NÃO & NÃO & NÃO & SIM & SIM \\
\hline Legenda & \multicolumn{5}{|l|}{ Significado } & & & & \\
\hline $\mathbf{E}$ & \multicolumn{5}{|l|}{ Entrevista } & & & & \\
\hline GF & \multicolumn{5}{|l|}{ Grupo focal } & & & & \\
\hline ET & \multicolumn{5}{|c|}{ Eutrófico } & & & & \\
\hline MII & \multicolumn{5}{|c|}{ Magreza grau II } & & & & \\
\hline MI & \multicolumn{5}{|c|}{ Magreza grau I } & & & & \\
\hline SB & \multicolumn{5}{|c|}{ Sobrepeso } & & & & \\
\hline OB & \multicolumn{5}{|c|}{ Obesidade } & & & & \\
\hline $\mathbf{S} / \mathbf{P C}$ & \multicolumn{5}{|c|}{ Sem preocupação com formato e tamanho do corpo } & & & & \\
\hline $\mathbf{P M}$ & \multicolumn{5}{|c|}{ Preocupação moderada } & & & & \\
\hline PL & \multicolumn{5}{|c|}{ Preocupação leve } & & & & \\
\hline PG & \multicolumn{5}{|c|}{ Preocupação grave } & & & & \\
\hline
\end{tabular}


Jaciara era uma jovem estudante universitária que possuía uma relação muito conflituosa com o seu corpo. Expressou sinais e sintomas de transtorno do comportamento alimentar em toda a sua narrativa, de forma direta, evidenciando mecanismos para purgar o que havia comido, comportamento compulsivo, uma preocupação excessiva com a comida, seu valor nutricional, sua preparação etc. "Aí eu comia um monte de doce num dia, aí tomava laxante e ficava no banheiro. Aí hoje, às vezes eu passo, sei lá, o final de semana inteiro comendo (Jaciara, branca)."

Mas também algumas atitudes, indiretamente, davam a ideia desse transtorno, como, por exemplo, não comer durante as trilhas que fazia, com a desculpa de que não gostava de evacuar no mato ou para não levar peso na mochila; ou lanchar ou comer pouco quando estava na faculdade, para economizar, devido ao valor da refeição. No entanto, ela mesma revelou que era uma pessoa que não tinha problemas financeiros, o que tornava as coisas mais fáceis na sua vida.

As atitudes de Jaciara diante dos transtornos alimentares estavam vinculadas não somente a sua própria insatisfação com o corpo, mas também à insatisfação dos seus familiares, mais especificamente sua mãe e seu irmão. Segundo ela, seu irmão também possuía uma forte preocupação com o corpo, que interferia no seu comportamento alimentar, mas a mãe tinha uma influência marcante nesse processo. Ela relatou a forte insatisfação da mãe com seu próprio corpo, o que a fez usar de diversas estratégias para conformá-lo a sua vontade. A última foi a cirurgia bariátrica, que promoveu a redução corporal.

Minha mãe é bem bunduda com um coxão assim, aí ela também tem a mesma coisa de odiar, se achar feia e querer usar roupas largas, essas coisas aí eu aprendi tudo com ela. (...) Porque eu... eu sempre achava que tava gorda. Eu tenho meio que a coxa grossa (riso) aí eu acho horrível (riso). Isso porque minha mãe também é assim. Eu até tomava os remédios dela pra emagrecer (risos), quando ela não aguentava, porque ela dizia que ficava muito nervosa. Ai eu pegava o resto dos remédios e tomava (Jaciara, branca).

Ao mesmo tempo que relatou momentos de jejum prolongado, Jaciara também externou a sua vontade de comer e a forma compulsiva pela qual às vezes fez isso, utilizando-se então de práticas diversas para evitar engordar.

Agora eu perdi um pouco a fome, eu perdi a fome mais, eu comecei a comer bem menos, é viajando, porque aí eu passava o dia inteiro sem comer, ou então fazendo trilha. (...) Eu como muito, eu como demais, assim, eu gosto de comer pratão, eu gosto de comer doce. Às vezes, eu como muito em um dia e no outro como pouco. Eu tento ficar equilibrando. (...) Às vezes quando eu como muita gordura eu tomo chá de carqueja, que diz que é bom (Jaciara, branca). 
Sua insatisfação com o corpo interferia inclusive nas suas relações afetivas. Afirmava que odiava quando seus namorados eram magros e altos, pois se sentia imensa ao lado deles. Dá preferência aos rapazes gordinhos e disse achar barriga grande em homens lindo, apesar de odiar barriga em mulheres e, principalmente, em si. No entanto, conseguia perceber o lado negativo da insatisfação com o corpo e dos comportamentos desordenados na alimentação, mas através da história de outros.

A questão importante evidenciada por esses resultados é a presença de história de transtorno alimentar em estudantes que se definiram como pretas, com experiência real de comportamentos alimentares desordenados. Apesar de nossa avaliação quantitativa demonstrar que as mulheres negras possuem menos riscos de desenvolver tais transtornos que as brancas, amarelas e indígenas, entre as estudantes que participaram da fase qualitativa da nossa investigação, foram essas as que expressaram mais diretamente tais problemas. Mas quem são essas jovens, quais as suas características, o que há de singular nas suas vidas ou comum entre elas?

Estrela era uma estudante de enfermagem de uma faculdade privada e possuía 24 anos na época da entrevista. É filha de casal separado, inter-racial, e morava com a mãe e os irmãos. Possuía um namorado há 12 anos. Declara-se preta, mas da raça humana. Não gosta do termo negro, pois associa à necrose e refere já ter sido discriminada por sua cor. Possui um conflito grande com o pai, a quem considera carrasco, por tentar usar os filhos para atingir a sua mãe.

Galáxia era uma estudante de medicina de uma universidade pública, de origem rural, tinha 21 anos. Vivia com uma renda de aproximadamente 1,5 salário mínimo mensal. Não se sentia discriminada por sua cor, no entanto, relatou já ter sofrido discriminação por se relacionar com pessoa negra, já ter sido rejeitada por vizinhos, amigos ou colegas e já ter sido mal atendida em uma loja por causa da sua cor. É a única entre os cinco filhos que não conhece o pai. Não tinha namorado e tinha poucos amigos.

Marisol era uma estudante de psicologia, de 19 anos, em uma universidade privada. Vivia com uma renda familiar de aproximadamente 7 salários mínimos. Disse que não se sentia discriminada e nem vivenciou situações de discriminação por causa da sua cor. Mas quando era criança dizia que era morena, pois não queria ser da cor que ninguém pintava. Filha de pais separados, tem três irmãos, dois da relação do pai com outra mulher. Relaciona-se bem com todos da família, com exceção da irmã (filha do outro relacionamento do pai). Não tinha namorado e tinha poucos amigos.

Sereia tinha 26 anos e cursava o segundo ano do ensino médio em um colégio público. Era empregada doméstica e vivia com uma renda familiar de aproximadamente 1 salário mínimo por mês. Filha de pais separados, tem quatro irmãs e teve um irmão assassinado por envolvimento com drogas. Vivia com seu companheiro e já perdeu um filho, por aborto espontâneo. Apresentou contradições entre o sentimento de discriminação racial e a vivência do racismo. No entanto, fez um longo relato de conflito com sua patroa, por questões raciais e de classe. 
Cora tinha 19 anos quando participou do grupo focal, cursava o $3^{\circ}$ ano do segundo grau, do ensino médio, de um colégio público. Vivia com renda familiar de mais ou menos um salário mínimo por mês. Nunca se sentiu discriminada ou vivenciou situações de discriminação por causa da sua cor. Morava com a mãe e a irmã.

\section{Discussão}

Para quatro dessas jovens negras o risco para transtornos alimentares esteve associado com a insatisfação com sua imagem corporal e com preocupações relacionadas com o formato e tamanho do corpo, mas nenhuma delas foi identificada pelo EAT-26, sugerindo um descompasso entre os resultados obtidos quantitativa e qualitativamente. Podemos inferir, a partir dessas informações, que, como já foi argumentado em alguns textos científicos, ${ }^{13,33}$ para pessoas com características raciais e étnicas diferentes dos euro-americanos, manifestações não detectáveis pelos testes de triagem podem indicar riscos para os transtornos do comportamento alimentar, o que reforça a importância da compreensão de como essas desordens se apresentam em grupos de outras etnias, com diferentes culturas e vivenciando situações de vida diferentes, para tal, utilizando instrumentos que valorizem essas diferenças em termos diagnósticos.

Já há uma discussão sobre a dificuldade de identificação dos sintomas de risco entre pessoas negras relacionados aos estereótipos quanto aos padrões corporais valorizados por elas e a proteção exercida pelas normas culturais tradicionais. ${ }^{34}$ A assunção dos valores corporais ocidentais, euroamericanos, aliados a fatores sociais, culturais e raciais podem vulnerabilizar mulheres que não se enxergam ou não se sentem acolhidas e representadas nesses padrões sociais.

Ao considerarmos que o corpo carrega a representação de valores e crenças assumidos socialmente, possuir atributos não reconhecidos nessa sociedade fere a integridade dessas pessoas, pois diz do lugar que estas assumem na sociedade e quais fatores estão influenciando na construção da sua identidade. ${ }^{35}$ Nesse sentido, já vem sendo documentada a pouca sensibilidade e/ou habilidade para diagnóstico das consequências de ser/estar no mundo de pessoas diversas etnicamente, expresso pelo corpo, visto que há a necessidade de ir além de marcadores corporais ou biológicos, mas estar atento aos diversos fatores que se imbricam nessa relação. ${ }^{33,36-38}$

Outro fator é que, ao contrário da associação que a literatura vem fazendo entre um maior IMC e insatisfação com a imagem corporal, predispondo aos transtornos alimentares, apenas uma das estudantes apresentava obesidade, todas as outras estavam eutróficas. A compulsão era o comportamento alimentar característico, às vezes seguido de purgação. Apenas Marisol citou uma dieta restritiva. O comportamento alimentar compulsivo vem sendo identificado como mais presente entre mulheres e homens negros com risco para transtorno alimentar em vários estudos internacionais ${ }^{38-40}$ realizados para tentar compreender a diferença de manifestação dessa desordem 
entre grupos diversos etnicamente, enquanto a restrição alimentar vem sendo relacionada com as caucasianas.

Há uma discussão ${ }^{41}$ sobre o mal-estar provocado pelos novos modus vivendi da sociedade contemporânea, caracterizada pela velocidade do crescimento tecnológico, levando a um acesso mais rápido às informações, pela valorização da estética e dos prazeres efêmeros. O hedonismo e o narcisismo contemporâneo fazem com que haja um investimento grande na aparência e no corpo, levando ao desencantamento pelas grandes causas e ao esvaziamento dos ideais. Ao mesmo tempo, as desigualdades no acesso aos bens e serviços oferecidos pelo mercado, a violência, inclusive contra o sexo feminino, e a exclusão social são também características desses novos tempos.

Há uma contradição provocada por essa sociedade que induz à busca de perfeição através do corpo, mas concomitantemente demoniza o prazer de comer, através da associação de determinados alimentos com a doença. Em paralelo, há uma divulgação intensa dos perigos associados à ingestão de alguns alimentos, da necessidade de realização de atividade física, da busca pela vida saudável, levando a um terrorismo alimentar, ao mesmo tempo que propagandas sobre delícias culinárias e lanches que têm seu sabor evidenciado pelo incremento de açúcar e gordura são veiculadas. Toda essa situação leva ao que se pode chamar de mal-estar da alimentação. Este, tanto pode levar a uma renúncia dos prazeres alimentares na tentativa de alcance dessa saúde física e, principalmente, aparência corporal, como o insucesso nessa empreitada pode gerar um descontentamento tal que favoreça o consumo alimentar excessivo como forma de válvula de escape emocional. ${ }^{41}$

O comer, do mesmo jeito que o sexo e o prazer, esteve relacionado com o pecado, o excesso e à falta de controle, e a partir dos anos 1960 as atitudes ascéticas foram sendo abandonadas devido a um processo crescente de liberação de costumes, de promoção da liberdade sexual, de independência feminina, em consequência da luta dos movimentos sociais. Atualmente, vivemos a cultura do prazer, da felicidade associada à satisfação de necessidades fugazes e superficiais. Pascal Brukner, citado por Nascimento, ${ }^{41}$ afirma que a "felicidade se tornou uma espécie de tirania do mundo contemporâneo”. E esta está ancorada no prazer, na estética corporal, na beleza. Quem não adere a esta fórmula de felicidade ou não consegue atingi-la, visto que a mesma não considera as diferenças e limitações dos seres humanos, está sujeito à vergonha, ao constrangimento e à pressão social. Nesse sentido, a compulsão alimentar pode também se apresentar como resposta à aflição gerada por esta incapacidade para atingir um ideal social de felicidade e prazer. Além disso, conflitos familiares ou relacionais, autoestima negativa, sentimento de solidão e características da personalidade podem se associar, nesse contexto social atual, para provocar descargas de comportamentos alimentares desgovernados.

Consoante com essas inferências há entre a maioria das garotas negras com risco para TCA uma sensação de falta de apoio, de não ter quem as ouça em momentos em que precisam compartilhar problemas e sentimentos, ou para aconselhá-las ou orientá-las como agir em situações difíceis. 
Parece que essas garotas experimentam um sentimento de solidão em momentos nos quais a presença de um outro significativo é fundamental para sentir-se integrada, ajustada e acolhida socialmente. Estrela, Marisol e Galáxia vivem conflitos familiares importantes e, da mesma forma que Sereia, não possuem convivência paterna. Aliado a esses conflitos familiares, expressam também o entendimento de que na sociedade a aceitação depende da cor da pele da pessoa, e, nesse sentido, as mulheres negras não são aceitas. Algumas informam a discriminação sofrida por questões raciais, outras afirmam que a discriminação ou rejeição foi por causa do corpo, mas acreditam que a modificação de algumas características as faria serem mais aceitas, respeitadas. A grande questão é que tais características são signos marcadores da condição racial negra.

As brancas, elas têm sim a ditadura da beleza também, mas eu acredito que seja menos porque elas já são aceitas pela cor que elas têm. As negras não, elas têm que se preocupar com a cor, na rua, racismo, têm que se preocupar com o cabelo duro que têm, que é da cor e tal, com aquela cor e tal, então elas são mais preocupadas, acho que tem... Então a gente vai se preocupar, além da cor, com o corpo, a gente tem que estar com o corpo magro, ela nem tanto, ela pode engordar um pouquinho, tal, se engordar ela vai pros Estados Unidos e vira uma modelo do GG, que agora é moda lá também, né (Marisol, negra).

Porque tem vezes mesmo que a menina não olha nem pra o corpo, mas sim que vê o rosto dela, às vezes enche de maquiagem, quer ter aquele cabelo liso, escovado assim bem reto, tipo Morticia Adams (risos), aí fica estranho. Porque as vezes tem negras que tem aquele cabelo enrolado, essa mesmo aqui que faz questão de deixar o cabelo dela assim (se refere à figura do painel - mulher negra com cabelo natural), eu acho, eu acho bem bonito um cabelo assim, mas tem gente que não gosta. A mídia pode não gostar, mas se a pessoas tá se sentindo bem, acho que ela, a, a...ela tem que ser assim (Talassa, branca).

A vivência de experiências de discriminação racial, percebida ou não dessa forma, junto com os conflitos familiares, a insatisfação com o corpo e a pressão externa para se ajustarem a um padrão estético, compõe um quadro de vulnerabilidade, que para cada jovem se manifesta de modo diferente, mas tem o comportamento alimentar como meio de expressão. Sereia tenta entender por que come escondido quando está na casa da patroa, e ela mesma suspeita que seja por se sentir tão incomodada com as atitudes racistas da mesma, que se sente confusa e questiona seu comportamento. Galáxia preocupa-se com a forma compulsiva como come e acredita que seja a maneira de lidar com insatisfações quanto aos seus relacionamentos interpessoais, devido ao seu pertencimento racial e social, mais que uma preocupação com o corpo.

O fato é que há uma interseção de fatores que se tangenciam com a forma como essas jovens se veem e se relacionam com o outro através dos seus corpos. Esse entrecruzamento de vulnerabilidades (de gênero, classe, raciais, familiares, de origem) as suscetibiliza para o estabelecimento de uma relação com seus corpos de rejeição, distanciamento, conflito, e o alimento ou, melhor, o comer, passa a ser a ferramenta que intermedia essa relação. Esses marcadores sociais que as diferencia são re(significados), à medida que se estabelecem em contextos que serão importantes na definição 
das identidades construídas e reconstruídas ${ }^{42}$ e é nesse momento que transtornos alimentares podem se estabelecer.

Outra questão que se percebe, de um modo geral, é que existem condições e/ou situações relacionadas aos transtornos alimentares que não foram detectadas pelo EAT-26. Com exceção de Jaciara (branca), as jovens que vivenciaram alguma situação de transtorno alimentar não apresentaram no EAT-26 valor suficiente para indicar esse risco. Podemos chamar essas situações de condições subclínicas, pois escapam aos critérios formais estabelecidos para identificação de risco para esses transtornos. Isso nos leva a acreditar na importância de desenvolvimento de estratégias de prevenção e de detecção desses riscos em pessoas que, necessariamente, ainda não apresentaram os sinais clássicos ou manifestaram o transtorno.

Já há uma discussão em torno da limitação dos testes diagnósticos para detectar uma ampla heterogeneidade de características envolvidas com esses distúrbios, principalmente quando pensamos em populações diversas culturalmente, etnicamente etc. Uma das explicações para esta insuficiente capacidade de detecção desses comportamentos é que tais testes foram desenhados com base em um conjunto de critérios euro-americanos e que são universalizados, desconsiderando diferenças étnicas e raciais. Outra consideração é que alguns vieses e estereótipos podem dificultar o diagnóstico nas distintas fases da vida, não identificando diferentes formas de manifestação clínica, ou mesmo formas subliminares, bem como a simultaneidade de sintomas. ${ }^{33,40}$

Comungando com essa lógica, no nosso estudo nem sempre a insatisfação com a imagem corporal e a preocupação com o tamanho e formato do corpo estiveram diretamente associadas com sinais e sintomas de risco para os transtornos alimentares, evidenciados pelo EAT-26. Isso aconteceu com Estrela (negra), que, apesar de ter satisfação em relação ao seu corpo, assumiu, em algum momento da sua vida, um comportamento, que, na interpretação dela mesma, seria de transtorno alimentar. Pode-se conjecturar que a relação e preocupação com a mãe tenham sido fatores decisivos para sua conduta, tanto de avaliação do seu próprio comportamento alimentar, como pela decisão de não querer repetir seus passos. No entanto, os valores do BSQ e do EAT-26 para essa estudante não indicaria que essa jovem pudesse ter alguma experiência relacionada com tais transtornos.

No caso de Sereia (negra), houve resultado positivo para preocupação com o formato e tamanho corporal, através do BSQ, mas negativo para o EAT-26, o que, numa leitura interpretativa desses valores, indicaria que tal preocupação não foi suficiente para levá-la a comportamentos sugestivos de transtorno alimentar, contrário ao vivenciado pela estudante. Já para Galáxia (negra), houve congruência entre o resultado do BSQ e a insatisfação corporal assumida por ela, no entanto, o resultado do EAT-26 de forma alguma levaria a pensar no comportamento alimentar compulsivo e até mesmo destrutivo apresentado por essa jovem. 
Evidencia-se como esses testes são importantes indicadores desse risco, mas não são suficientes para abarcar a complexidade envolvida no desenvolvimento de tais transtornos, principalmente entre pessoas de raça/etnia diversa do euro-americano. Mesmo considerando a importância de testes como o EAT no processo de identificação dos transtornos alimentares, o estabelecimento de outras técnicas mais sensíveis que possam dar conta dessa situação mais sutil e o desenvolvimento de discussões entre os jovens, não apenas sobre os transtornos, mas sobre os fatores que estão envolvidos, pode ser de grande utilidade na diminuição da incidência dos mesmos.

Oliveira \& Hutz, ${ }^{43}$ ao fazer uma discussão teórica sobre os fatores culturais envolvidos no aumento do número de transtornos alimentares, sugerem que estudos interdisciplinares e de desenho qualitativo poderiam dar conta com maior profundidade da complexidade desses fenômenos, bem como do impacto da imagem corporal nas práticas alimentares. Por outro lado, também se defende a ideia de que o diálogo entre essas duas abordagens, que oferecem informações de natureza diferentes (as investigações quantitativas privilegiando o objetivo, factual e tangível, possível de ser quantificado e analisado estatisticamente e a abordagem qualitativa evidenciando o subjetivo, emocional e individual, possível de ser alcançado através de uma análise construtiva e interpretativa), seja mais eficiente na produção de conhecimentos que permitam compreender e agir de forma mais efetiva em termos preventivos e resolutivos. ${ }^{44}$

Isso comunga com a ideia de Csordas, de que a abordagem fenomenológica, na qual "o corpo não é um objeto a ser estudado em relação à cultura, mas é o sujeito ou base existencial da cultura”, ${ }^{40}$ seria a mais interessante para entender o paradigma da corporeidade. Ele se baseia nas visões de Merleau Ponty sobre a percepção do corpo indo além da dualidade sujeito/objeto, visto que há sempre mais do que é possível perceber através dos olhos, e do entendimento de Bourdieu, de que o corpo socialmente informado, ou seja, o habitus, é o princípio gerador e unificador de todas as práticas sociais. ${ }^{45}$

Alguns autores ${ }^{46}$ defendem que a experiência dos transtornos alimentares está relacionada com a tentativa de vivência corporal no sentido de alcançar um corpo desejado, estabelecido social e culturalmente, que ultrapassa as possibilidades biológicas e histórico-subjetivas do próprio corpo. A configuração do corpo desejado se estabelece através do olhar e avaliação do outro, das experiências, expressões e práticas discursivas do outro, que emergem a partir do corpo. Nesse sentido, há uma conversão dos discursos sociais em trama pessoal, configurando-se, dessa maneira, na identidade dessas jovens. Em consequência disso, eles defendem que a vivência corporal é subjetiva, possível de ser narrada, mesmo que não se esgote nos relatos, e que a configuração corporal possibilita uma forma particular de se narrar, de se relacionar com os outros e de estabelecer para si um lugar em um grupo social. Assim sendo, a narrativa de sua vivência corporal, suas práticas e sentimentos permite ressignificá-las, bem como sua história, possibilitando mudanças, inclusive da compreensão desta corporalidade. 


\section{Conclusão}

O que podemos concluir de todos esses relatos é que há presença de comportamento alimentar desordenado entre algumas estudantes que se definiram como pretas, e entre os fatores associados aos mesmos estão conflitos familiares, a vivência ou percepção do racismo, o sentimento de falta de apoio social em momentos importantes da vida, bem como a insatisfação com a imagem corporal e a compulsão alimentar. Percebemos, então, o desregramento do corpo como marcador do que está fora de ordem no mundo psicossocial. A experiência da transformação do corpo se apresenta como termômetro de relações sociais disruptivas e como indicadora de encarnação de sofrimento. ${ }^{47}$

A vivência do racismo, associada com conflitos familiares, expressos mais fortemente pela relação com a mãe, seja essa relação de identificação, rejeição ou pressão para se conformar a determinado padrão, a comparação com outras mulheres e os papéis que representam na sociedade, questões de classe, manifestas no pertencimento a grupos sociais diferentes, são elementos que se interseccionam para vulnerabilizar as jovens.

Apesar do sugerido pela análise estatística, encontramos, em uma análise mais aprofundada com 18 garotas, cinco estudantes negras que vivenciaram diretamente comportamentos alimentares desordenados e duas que, indiretamente, apresentaram algum tipo de relação com essa experiência. Esse fato contradiz o que os resultados dos testes de triagem para essas garotas demonstraram, o que nos levou a refletir sobre a necessidade de utilização de uma conjugação de abordagens quantitativas e qualitativas para investigar e compreender como esses transtornos vêm crescendo no mundo todo, quais os fatores envolvidos e quais as formas de prevenção e tratamento mais eficazes.

As narrativas deste estudo nos revelaram experiências e situações que permitiram entender melhor a corporalidade das estudantes e a relação com os transtornos alimentares, mesmo quando estes não eram diretamente vividos por elas. Vivenciar histórias de transtorno alimentar através de familiares e amigos próximos não significa ter risco direto para essas desordens, mas diz um pouco dos valores e crenças que rodeiam essas pessoas e da possibilidade de interferência em suas próprias crenças e valores. Sabemos que entre jovens, a referência do outro e a necessidade de corresponder, de se sentir fazendo parte de algo, de algum grupo ou comunidade, mobiliza a construção de identidade e as suas atitudes concretas.

Ter como referência pessoas para as quais a relação com o corpo passa pela busca da perfeição de um corpo que não apresenta similaridade com o seu, mas que, acredita, pode ser manipulado e moldado para atender aos desejos de felicidade, sucesso e conquista tem sido frequente na sociedade atual. Nesta, o corpo passou a ser visto como algo fora de mim, mas que, ao mesmo tempo, diz quem eu sou e possui um valor de mercado. É esse valor de mercado cada vez mais alto que me impulsiona a tomar atitudes para transformá-lo no que eu preciso para atender aos imperativos de uma sociedade para a qual quem eu sou, além do corpo que eu apresento, não 
possui tanto significado assim. Parece-me então que existe uma linha tênue entre as atitudes de busca desse ideal corporal e atitudes alimentares desordenadas que pode ter como consequência os transtornos alimentares.

A questão é que esse outro é heterogêneo, com visões diferentes sobre qual é o modelo necessário para se alcançar o êxito e sucesso na vida. E no caso das mulheres negras, a sua aparência frequentemente se apresenta como uma ameaça para atingir o sucesso que permitirá um lugar social, influenciando dessa forma, de maneiras diferentes, a vivência corporal e a construção da identidade de jovens para quem esse outro e sua avaliação é fundamental, podendo levar ao patológico e à enfermidade. O que é normal e o que é patológico na ótica de quem vive um transtorno alimentar possui conotações diferentes, pois há outra perspectiva que alimenta as escolhas e comportamentos dessas pessoas. A busca pela perfeição e do controle de si e da própria vida, a partir do controle do corpo, sustenta a convicção pelo caminho escolhido ou pela crença que não há outro possível.

\section{Colaboradores}

Bittencourt LJ e Nunes MO: as autoras participaram de todas as etapas de elaboração do trabalho, da construção do projeto até a elaboração do artigo.

Conflito de Interesses: Os autores declaram não haver conflito de interesses.

\section{Referências}

1. Alves TCHS, Santana MLP, Silva RCR, Pinto EJ, Assis AMO. Fatores associados a sintomas de transtornos alimentares entre escolares da rede pública da cidade do Salvador, Bahia. J Bras Psiquiatr. 2012; 61(2):55-63.

2. Martins CR, Pelegrini A, Matheus SC, Petroski EL. Insatisfação com a imagem corporal e relação com estado nutricional, adiposidade corporal e sintomas de anorexia e bulimia em adolescentes. Rev Psiquiatr RS. 2010; 32(1):19-23.

3. Lynch WC, Heil DP, Wagner E, Havens MD. Body Dissatisfaction Mediates the Association between Body Mass Index and Risky Weight Control Behaviors among White and Native American Adolescent Girls. Appetite 2008; 51(1):210-3.

4. Giordani RCF. A Auto-Imagem Corporal na Anorexia Nervosa: Uma Abordagem Sociológica. Psicol Soc. 2006; 18(2):81-8.

5. Bosi MLM, Uchimura KY, Luiz RR. Eating behavior and body image among psychology students. J Bras Psiquiatr. 2009; 58(3):150-5. 
6. Gonçalves TD, Barbosa MP, Rosa LCL, Rodrigues AM. Comportamento anoréxico e percepção corporal em universitários. J Bras Psiquiatr. 2008; 57(3):166-70.

7. Kirsten VR, Fratton F, Porta NBD. Transtornos alimentares em alunas de nutrição do Rio Grande do Sul. Rev. Nutr. 2009; 22(2):219-27.

8. Ramberan K, Austin M, Nichols S. Ethnicity, body image perception and weight-related behaviour among adolescent females attending secondary school in Trinidad. West Indian Med J. 2006; 55(6):388-93.

9. McLaughlin KA, Hilt LM, Nolen-Hoeksema S. Racial/ethnic differences in internalizing and externalizing symptoms in adolescents. J Abnormal Child Psychol. 2007; 35(5):801-16.

10. Walcot DD, Pratt HD, Patel DR. Adolescents and eating disorders: gender, racial, ethnic, sociocultural, and socioeconomic issues. Journal of Adolescent Research 2003; 18(3):223-43.

11. Grilo CM, Lozano C, Masheb RM. Ethnicity and sampling bias in binge eating disorder: black women who seek treatment have different characteristics than those who do not. Int J Eat Disord. 2005; 38:257-62.

12. Szabo CP, Allwood CW. Body figure preference in South African adolescent females: a cross cultural study. African Health Sciences. 2006; 6(4):201-6.

13. Wood NAR, Petrie TA. Body dissatisfaction, ethnic identity, and disordered eating among african american women. J Couns Psychol. 2010; 57(2):141-53.

14. Morgan CM, VecchiattiIR, Negrão AB. Etiologia dos transtornos alimentares: aspectos biológicos, psicológicos e sócio-culturais. Rev Bras Psiquiatr. 2002; 24(Supl III):18-23.

15. Vitolo MR, Bortolini GA, Horta RL. Prevalência de compulsão alimentar entre universitárias de diversas áreas de estudo. Rev Psquiatr RS. 2006; 28(1):20-6.

16. Rech CR, Araújo EDS, Vanat JDR. Autopercepção da imagem corporal em estudantes do curso de educação física. Rev. Bras. Educ. Fís. Esporte 2010; 24(2):285-92.

17. Alvarenga MS, Phillipi ST, Lourenço BH, Sato PM, Scagliusi FB. Insatisfação com a Imagem Corporal em Universitárias Brasileiras. J Bras Psiquiatr. 2010; 59(1):44-51.

18. Vilela JEM, Lamounier JÁ, Dellaretti Filho MA, Barros Neto JR, Horta GM. Transtornos alimentares em escolares. J. Pediatr. 2004; 80(1):49-54.

19. Bosi MLM, Luiz RR, Morgado CMC, Costa MLS, Carvalho RJ. Autopercepção da imagem corporal entre estudantes de nutrição: um estudo no município do Rio de Janeiro. J Bras Psquiatr. 2006; 55(2):108-113.

20. Cachelin FM, Striegel-Moore RH. Help Seeking and Barriers to treatment in a community Sample of Mexican American and European American Women with Eating Disorders. Int J Eat Disord. 2006; 39:154-161.

21. Brasil. Ministério da Saúde. Secretaria de Atenção à Saúde. Departamento de Atenção Básica. Coordenação Geral da Política de Alimentação e Nutrição. Vigilância Alimentar e Nutricional. SISVAN: orientações básicas para a coleta e análise de dados antropométricos em serviços de saúde. Brasília: Ministério da Saúde; 2008. 
22. World Health Organization. Obesity: preventing and managing the global epidemic. Reportof a WHO Consultation of Obesity. Geneva: WHO; 1997.

23. Brasil. Ministério da Saúde. Curva IMC por Idade Meninas dos 5 aos 19 anos (percentis) [Internet]. Brasília: Ministério da Saúde; 2007. [acesso em: 13 abr. 2008]. Disponível em: http//:www.saude.gov.br.

24. Freitas S, Gorenstein C, Appolinario JC. Instrumentos para avaliação dos transtornos alimentares. Rev Bras Psiquiatr. 2002; 24(Supl. III):34-8.

25. Bighetti F, Santos CB, Santos JE, Ribeiro RPP. Tradução e validação do Eating Attitudes Test em adolescentes do sexo feminino de Ribeirão Preto-SP. J Bras Psiquiatr. 2004; 53(6):339-46.

26. Nunes MA, Bagatini LF, Abuchaim AL, Kunz A, Ramos D, Silva JA, et al. Distúrbios da conduta alimentar: consideraçöes sobre o Teste de Atitudes Alimentares (EAT). Rev. ABP-APAL 1994; 16(1):7-10.

27. Magalhães VC, Mendonça GAS. Transtornos alimentares em universitárias: estudo de confiabilidade da versão brasileira de questionários autopreenchíveis. Rev Bras Epidemiol. 2005; 8(3):236-45.

28. Cordás TA, Neves JEP. Escalas de avaliação de transtornos alimentares. Rev Psiquiatr Clín. 1999; 26(n.esp1):41-47.

29. Di Pietro M, Silveira DX. Internal validity, dimensionality and performance of the Body Shape Questionnaire in a group of Brazilian college students. Rev Bras Psiquiatr. 2009; 31(1):21-4.

30. Conti MA, Cordás TA, Latorre MRDO. A study of the validity and reability of the brazilian version of the Body Shape Questionnaire (BSQ) among Adolescents. Rev Bras Saúde Matern Infant. 2009; $9(3): 331-338$.

31. Thompson JB. A metodologia da interpretação. In: Thompson JB. Ideologia e cultura moderna. Teoria social crítica na era dos meios de comunicação de massa. Petrópolis, RJ: Vozes; 1995. p. 355-419.

32. Carvalho ICM. Biografia, identidade e narrativa: elementos para uma análise hermenêutica. Horizontes Antropológicos 2003; 9(19):283-302.

33. George JBE, Franko DL. Cultural issues in eating pathology and body image among children and adolescents. J Pediatr Psychol. 2010; 35(3):231-42.

34. Striegel-Moore RH, Rosselli F, Holtzman N, Dierker L, Becker AE, Swaney G. Behavioral symptoms of eating disorders in native americans: results from the add Health Survey Wave III. Int J Eat Disord. 2011; 44(6):561-6.

35. NogueiraI B. O corpo da mulher negra. Revista de Psicanálise 1999; XIII(135):40-5.

36. Talleyrand RM. Eating disorders in african american girls: implications for counselors. Journal of Counseling and Development 2010; 88:319-24.

37. Marques L, Alegria M, Becker AE, Chen C, Fang A, Chosak A et al. Comparative prevalence, correlates of impairment, and service utilization for eating disorders across us ethnic groups: implications for reducing ethnic disparities in health care access for eating disorders. Int J Eat Disord. 2011; 44(5):412-20.

38. Pike KM, Dohm F, Striegel-Moore RH, Wilfley DE, Fairburn CG. A comparison of black and white binge eating disorder. Am J Psychiatry 2001; 158:1455-60. 
39. Taylor JY, Caldwell CH, Baser RE, Nakesha F. Prevalence of eating disorders among blacks in the National Survey of American Life. Int J Eat Disord. 2007; 40(Supl.):S10-S14.

40. Thomas JJ, Crosby RD, Wonderlich SA, Striegel-Moore RH, Becker AE. A latent profile analysis of the typology of bulimic symptoms in an indigenous Pacific population: evidence of cross-cultural variation in phenomenology. Psychological Medicine 2011; 41:195-206.

41. Nascimento AB. Comida: prazeres, gozos e transgressões. 2 ed. Salvador: EDUFBA; 2007.

42. Mariano SA, Macêdo MS. Desigualdades e interseccionalidades: deslindando a complexa trama das hierarquias e agenciamentos. Mediações 2015; 20(2):11-26.

43. Oliveira LL, Hutz CS. Transtornos alimentares: o papel dos aspectos culturais no mundo contemporâneo. Psicologia em Estudo 2010; 15(3):575-82.

44. López Coutiño L, Torres López TM. La investigación cuantitativa y cualitativa sobre anorexia. Rev Salud Pública Nutr. [Internet]. 2009; 10(2). Disponível em: http://www.medigraphic.com/pdfs/ revsalpubnut/spn-2009/spn092i.pdf

45. Csordas TA. Corporeidade como um paradigma para a antropologia. In: Csordas T. Corpo/significado/ cura. Porto Alegre: Editora da UFRGS; 2008. p.101-46.

46. Hernández MHB, Cortés AFM. Cuerpo vivido e identidad narrativa em mujeres diagnosticadas con transtornos de la conducta alimentaria. Rev. Colomb. Psiquiat. 2010; 39(3):544-55.

47. Nunes MO, Bittencourt LJ. No rastro do que transtorna o corpo e desregra o comer: os sentidos do descontrole de si e das "compulsões alimentares". Interface - Comunic. Saúde Educ. 2013; 16(44):145-57.

Recebido: 23/3/2016

Revisado: 29/9/2016

Aceito: 28/1/2017 